\title{
The Study of Biochemical Markers in Chronic Renal Failure Patients in Pre- and Post- Haemodialysis
}

\author{
Mohammed Abed Jawad', Abed J Kadhim ${ }^{2}$ \\ ${ }^{1,2} \mathrm{Al}$-Nisour University College, Iraq. \\ DOI: https://doi.org/10.24321/0019.5138.202166
}

\section{I $\quad \mathbf{N} \quad \mathbf{F} \quad \mathbf{O}$}

\section{Corresponding Author:}

Mohammed Abed Jawad, Al-Nisour University College, Iraq.

E-mail Id:

mohammed.a.medical.lab@nuc.edu.iq

Orcid Id:

https://orcid.org/0000-0002-0219-086X

How to cite this article:

Jawad MA, Kadhim AJ. The Study of Biochemical Markers in Chronic Renal Failure Patients in Pre- and Post-Haemodialysis. J Commun Dis. 2021;53(3):259-264.

Date of Submission: 2021-08-20

Date of Acceptance: 2021-09-12

\section{$\begin{array}{llllllll}\mathbf{A} & \mathbf{B} & \mathbf{S} & \mathbf{T} & \mathbf{R} & \mathbf{A} & \mathbf{C} & \mathbf{T}\end{array}$}

Background: The current research is designed to investigate alterations in lipid peroxidation (malondialdehyde - MDA) and renal markers (urea and creatinine) in patients of chronic renal failure (CRF) as compared to the control group.

Method: The study included 55 subjects, who were separated into two groups: control group, which included 15 healthy members with no history of systematic illness; and patients group, which included 40 patients with CRF divided into four groups "Non: CRF patients without any accompanied disease, DM: CRF patients with diabetes mellitus, HT: CRF patients with hypertension, and HT + DM: CRF patients with diabetes mellitus and hypertension".

Results: The findings reveal that there is a notable increase in serum concentration of MDA, urea, and creatinine, in patients group as compared to the control group.

Conclusion: In all chronic renal failure patients with or without any accompanying disease, lipid peroxidation is present in pre- and posthaemodialysis patients as well as patients with CRF have high levels of urea and creatinine compared with healthy groups.

Keywords: Renal Failure, Malondialdehyde (MDA), Blood Urea Concentration (BUC), Creatinine ( $\mathrm{Cr}$ )

\section{Introduction}

Renal failure means a situation in which the kidney has lost its normal functioning, which may occur as a consequence of different influences, including infections, autoimmune conditions, diabetes and endocrine, cancer and toxic substances. The ninth biggest cause of death in both the United States and many developed nations in the world is a decrease in the excremental and regulating functions of the renal. ${ }^{1}$ Renal insufficiency may be acute or chronic. ${ }^{2}$
Acute renal failure means that renal function is declining rapidly enough to improve blood levels in nitrogen waste and to damage fluid and electrolyte balance. ${ }^{3}$ Chronic renal failure (CRF) is, on either hand, the gradual and permanent loss of kidney structures. ${ }^{4} \mathrm{~A}$ multitude of diseases, including long-term hypertension, diabetes and congenital renal diseases can result in chronic renal failure; diabetes is the major cause of chronic renal failure and is linked to increased cardiovascular morbidity and death. ${ }^{5}$ Many oxidative strain biomarkers in CRF patients have 
been demonstrated to be high, including lipid oxidation products "lipid peroxides, malondialdehyde". ${ }^{2}$ Impaired oxidative balance in CRF can originate from an elevated production (ROS) combined and decreased clearance and an inefficient antioxidant defence. ${ }^{6} \mathrm{CRF}$ patients also suffer from increased oxidative stress through diminished systems of antioxidants and increased activity of prooxidants. ${ }^{4}$ Polyunsaturated fatty acids (PUFAs) are oxidised in vivo in cell membranes and generate aldehydes of varied chain lengths like malondialdehyde (MDA). Structural altering of this buttocking product may involve DNA, RNA, protein body, and other biomolecules. ${ }^{5,7-10}$

\section{Materials \& Methods}

Standard operating procedures (SOPs) have been followed in conducting the study protocols in Baghdad City, Iraq.

\section{Collection of Blood Samples}

Blood samples $(5 \mathrm{~mL}$ ) have been obtained from patients suffering from chronic renal failure (CRF) and control. Blood samples were placed without anticoagulants in simple tubes. Samples could be clotted for 30 minutes at room temperature in order to produce a clot then centrifuged for 10 minutes at 3000 rotors per minute (rpm) to yield sera. ${ }^{11}$ Until a biochemical analysis, Sera was extracted and stored $\left(-200^{\circ} \mathrm{C}\right)$ unless it was immediately utilized. ${ }^{12}$

\section{Serum Malondialdehyde Concentrations Determination (MDA): Principle}

The thiobarbituric acid technique was used to establish lipid peroxidation. ${ }^{13}$ MDA was generated as the LPO product which combines with Thiobarbituric acid (TBA) in coexisting TCA to produce a red chromophore absorption at $532 \mathrm{~nm}$ by degeneration of polyunsaturated fatty acids.

The plasma MDA concentration was based on the following equation:

$$
\begin{aligned}
& \text { equation: } \\
& \text { Plasma MDA (nmol } / \mathrm{mL})=\frac{A \text { sample }-A \text { blank }}{\mathcal{E}_{M D A}}=\frac{\Delta A}{1.56} \times 10^{3} \\
& \text { Determination of Urea Concentration }
\end{aligned}
$$

The approach is based on the equation below:

$$
\text { Urea }+\mathrm{H}_{2} \mathrm{O} \longrightarrow \text { Urease } \longrightarrow 2 \mathrm{NH}_{3}+\mathrm{CO}_{2}
$$

The ammonium ion reacts with the salicylate and hypochlorite in the reagent to generate a green complex (2, 2 dicarboxylindo-phenol) that absorbs at $600 \mathrm{~nm}$. The following equation was used to compute the concentration of urea:

Urea Concentration $(\mathbf{m g} / \mathbf{d L})=\frac{\text { A. of sample }}{\text { A. of stander }} \times 50$

Determination of Serum Creatinine Concentration

Picric acid interacts with creatinine in an alkaline solution to generate a colourful complex. The amount of complex produced is proportional to the concentration of creatinine. ${ }^{14}$ The following equation was used to compute the concentration of urea:

Creatinine Concentration $(\mu \mathrm{mol} / \mathrm{I})=\Delta \mathrm{A}_{\text {sample }} / \Delta \mathrm{A}_{\text {standard }} 177$
Results and Discussion

\section{Malondialdehyde Concentration (MDA)}

Table 1 and Figure 1 show that in all patient groups before and after HD there is a significant increase $(p=0.05)$ in serum MDA levels in comparison to the control group. The results of the MDA study are compared with other studies ${ }^{15}$ supporting the conclusion that the MDA in CRF patients is increased in comparison to controls and the severity of the condition is elevated. Further, it also demonstrated substantial differences in serum MDA levels among all groups of pre-HD patients. However, serum MDA levels indicated a substantial increase in HT+DM compared to DM and non-groups in the group of patients, following the haemodialysis. In addition, HT indicated that the serum level MDA was significantly higher than DM and nongroups, although non-significant variations in MDA levels between non-group and DM groups could be noted. Also, the differences between the HT+DM group and the HT group in the Post-HD are not significant at the MDA level. In contrast, a substantial decrease in MDA in all Post-HD patient groups has been observed in serum peroxidation in the serum of CRF patients, as compared with pre-HD (within the exception of the HT+DM patient groups, the Serum MDA level in Post-HD shows no significant decreases in comparison with pre-HD). The present findings are consistent with ${ }^{16,17}$ investigations which showed serum MDA to promote lipid peroxidation in uremic patients when MDA is increased and HD therapy leads to a decrease in this peroxidation in circulating cells. ${ }^{18}$ The intradialytic MDA was found to be reduced. The tiny water-soluble molecule, like MDA, can spread through the membranes of dialysis. Taking MDA clearance into account during dialysis, any increase in intradian MDA levels indicates that oxidative stress will be present throughout dialysis. However, the present study contradicts with ${ }^{19}$ the investigations that reported that serum MDA in the post-dialysis group was increasing compared to predialysis. Renal failure disorders in enzyme pathways for free radicals, detoxification, and the development of lipid peroxidation products, such as MDA, lead to altered antioxidant systems and reactive oxygen species (ROS). Lipid peroxidant compounds can contribute to endothelial damage and can participate in atherosclerosis formation. ${ }^{20}$ Post dialysis MDA monitoring is highly important for future perspectives. 
Table I.Serum Malondialdehyde Level in All Studied Groups

\begin{tabular}{|c|c|c|c|}
\hline \multirow{2}{*}{ Groups } & \multirow{2}{*}{$\mathbf{n}$} & \multicolumn{2}{|c|}{ MDA $(\mu \mathrm{mol} / \mathrm{L})$ Mean \pm SD } \\
\hline & & Post-dialysis & Pre-dialysis \\
\hline Non & 10 & $190.90 \pm 40.23^{a *}$ & $139.10 \pm 40.16^{\mathrm{b} * *}$ \\
\hline DM & 10 & $173.20 \pm 51.13^{a *}$ & $137.12 \pm 51.88^{\mathrm{b} * *}$ \\
\hline HT & 10 & $188.88 \pm 56.39^{a *}$ & $161.33 \pm 50.13^{a * *}$ \\
\hline $\mathrm{HT}+\mathrm{DM}$ & 10 & $178.30 \pm 54.18^{a *}$ & $171.00 \pm 48.74^{\mathrm{a} *}$ \\
\hline Control & 15 & $16.18 \pm 2.11^{b *}$ & $16.91 \pm 2.15^{c *}$ \\
\hline \multicolumn{2}{|c|}{ LSD } & 17.93 & 15.904 \\
\hline
\end{tabular}

$a, b, c$ refer to significant differences among groups.

* significant at $p$ value less than $5 \%$

** significant at $\mathrm{p}$ value less than $1 \%$

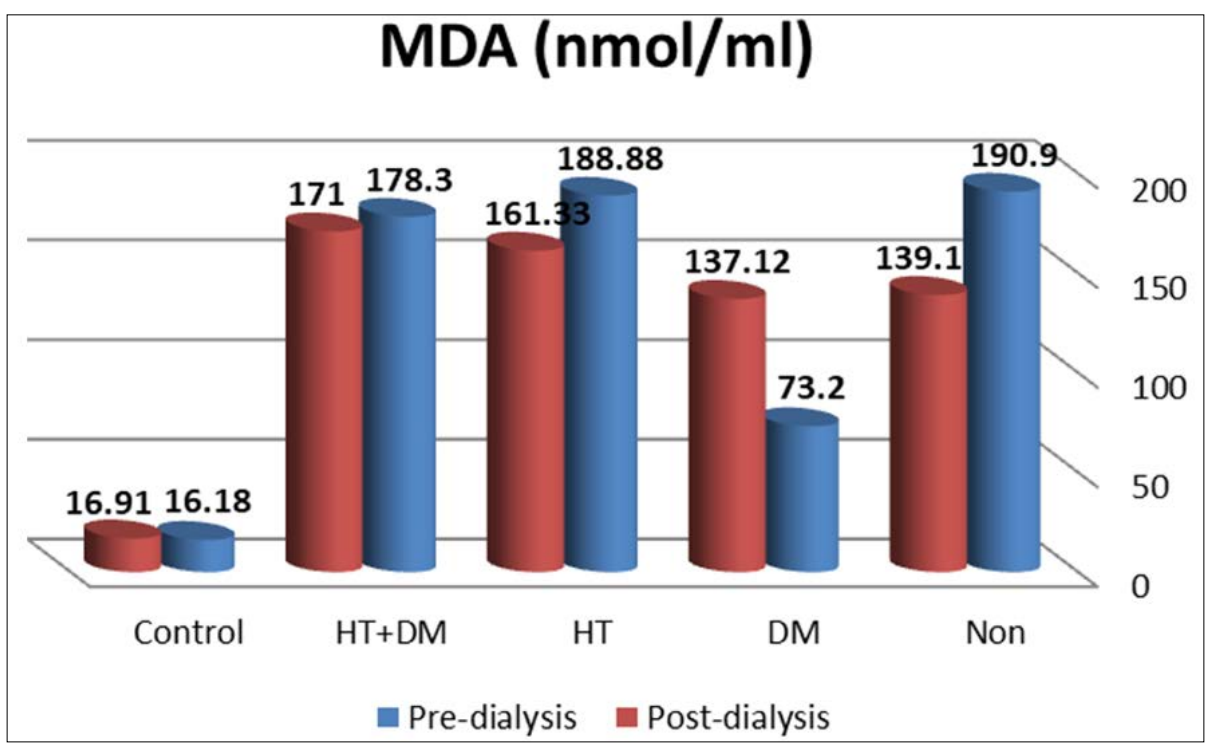

Figure I.Serum Malondialdehyde Level

Table 2.Blood Urea Concentration in All Studied Groups

\begin{tabular}{|c|c|c|c|}
\hline \multirow{2}{*}{ Groups } & \multirow{2}{*}{$\mathbf{n}$} & \multicolumn{2}{c|}{ S. Creatinine $(\boldsymbol{\mu m o l} / \mathrm{L})$ Mean \pm SD } \\
\cline { 3 - 4 } & & Post-dialysis & $12.67 \pm 3.19^{\mathrm{b} * *}$ \\
\hline Non & 10 & $23.66 \pm 4.83^{\mathrm{b} *}$ & $15.28 \pm 5.19^{\mathrm{a} * *}$ \\
\hline DM & 10 & $27.83 \pm 7.99^{\mathrm{a} *}$ & $11.29 \pm 3.00^{\mathrm{b} * *}$ \\
\hline HT & 10 & $23.4 \pm 6.80^{\mathrm{b} *}$ & $13.1 \pm 6.17^{\mathrm{a} * *}$ \\
\hline HT+DM & 10 & $26.2 \pm 9.32^{\mathrm{a} *}$ & $2.79 \pm 1.20^{\mathrm{c} *}$ \\
\hline Control & 15 & $3.77 \pm 0.98^{\mathrm{c} *}$ & 1.03 \\
\hline
\end{tabular}

a,b,c refer to significant differences among groups.

* significant at $p$ value less than $5 \%$.

** significant at $\mathrm{p}$ value less than $1 \%$.

\section{Blood Urea Concentration (BUC)}

In all patient groups in the pre- and post-HD group, Table 2 and Figure 2 demonstrate a substantial increase $(p<0.05)$ in blood urea concentration) as compared to the control groups. This study has been conducted according to numerous studies by Rayner $\mathrm{H}$ et al. ${ }^{21}$ However, in comparison to 
the HT+DM group, the blood urea concentration in the DM group did not significantly rise before haemodialysis. In comparison to non and HT, BUC in the DM group increases dramatically. In addition, in comparison with the non and the HT groups, the HT+DM group showed a notable increase in serum urea concentration, but the non-group showed an unprecedented increase in serum urea concentration compared to the HT group of patients before HD. In addition, DM and HT+DM groups of patients showed non-significant differences between each other after haemodialysis. However, in comparison with the Non and HT group of patients, patient groups in DM and HT\&DM showed significant increases in serum urea levels, whereas those in the HT group showed a non-significant increase in HT patients' concentration. The serum urea concentration demonstrated, on the other hand, a significant drop in postHD groups of all patients compared to pre-HD numbers in the current investigation.

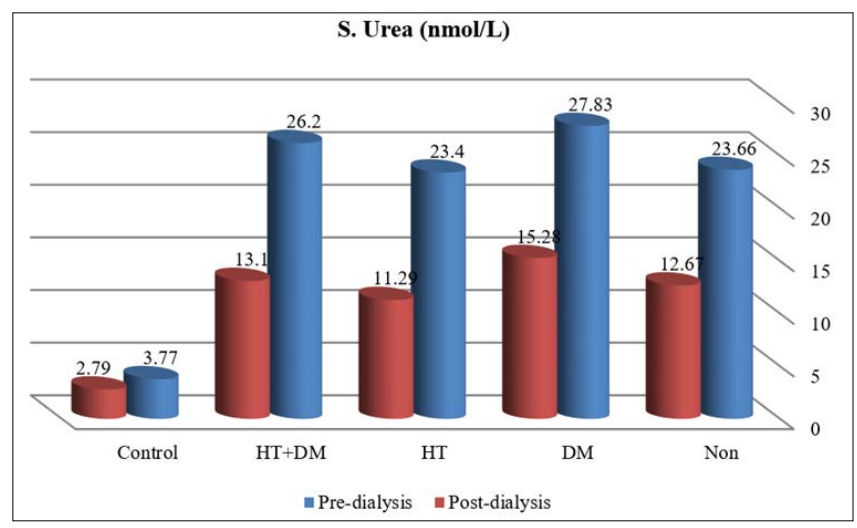

Figure 2.Blood Urea Concentration

This is consistent with the results of the research. ${ }^{22}$ The removal of small molecules during dialysis depends on a membrane structure for hydrodynamic conditions as the predominant blood-transport resistance is not in the membrane, but in the boundary layers close to the membrane. ${ }^{23}$ Urea and creatinine are the most major substances discharged by the kidney and the first organic solution found in CRF patients' blood. This rise in urea is due to the ability of the kidneys in CRF to remove nitrogenic waste from the blood leading to the accumulation of these compounds in the blood. ${ }^{24}$

\section{Serum Creatinine Concentration (Cr)}

In comparison with the control group, Table 3 and Figure 3 demonstrate substantial elevation ( $p \sim 0.05$ ) in serum creatinine concentration in all patient groups in pre- and post-HD. These findings are based on a prior study by Valko $M$ et al. ${ }^{25}$ However, before haemodialysis, in the patients of non, DM, and HT groups, there had been no significant changes in serum creatinine compared, but the group of patients with HT+DM had shown a substantial increase in creatinine levels compared to the patients of non, DM, and HT groups. Similarly, serum creatinine concentrations were significantly increasing in the group of HT+DM patients compared with the patients of non, DM, and HT groups following haemodialysis. In addition, serum creatinine levels were significantly higher in the HT group than in serum creatinine levels in the DM group, while in the HT patients' group, serum creatinine levels had not been significantly increased in comparison with the non-patients' group. Likewise, a significant increase in serum $\mathrm{Cr}$ levels relative to the DM group has also been shown by a group of non-patients.

Table 3.Serum Creatinine Concentration in All Studied Groups

\begin{tabular}{|c|c|c|c|}
\hline \multirow{2}{*}{ Groups } & \multirow{2}{*}{$\mathbf{n}$} & \multicolumn{2}{|c|}{ S. Creatinine ( $\boldsymbol{\mu m o l} / \mathrm{L})$ Mean \pm SD } \\
\cline { 3 - 4 } & & Post-dialysis & Pre-dialysis \\
\hline \multirow{2}{*}{ Non } & 10 & $499.05 \pm 142.58^{\mathrm{b} *}$ & $\begin{array}{c}294.41 \pm 81.80^{\mathrm{b}} \\
\mathrm{c**}\end{array}$ \\
\hline \multirow{2}{*}{ DM } & 10 & $317.02 \pm 128.06^{\mathrm{b} *}$ & $\begin{array}{c}272.29 \pm \\
88.15^{\mathrm{c} * *}\end{array}$ \\
\hline HT & 10 & $422.02 \pm 129.73^{\mathrm{b} *}$ & $\begin{array}{c}239.22 \pm \\
81.96^{\mathrm{b} * *}\end{array}$ \\
\hline HT+DM & 10 & $489.36 \pm 190.45^{\mathrm{a} *}$ & $\begin{array}{c}360.43 \pm \\
148.17^{\mathrm{a} *}\end{array}$ \\
\hline Control & 15 & $77.75 \pm 22.88^{\mathrm{c} *}$ & $78.15 \pm 83.10^{\mathrm{d} *}$ \\
\hline \multicolumn{2}{|c|}{ LSD } & 39.13 & 34.95 \\
\hline
\end{tabular}

a,b,c refer to significant differences among groups.

* significant at $p$ value less than $5 \%$

** significant at $\mathrm{p}$ value less than $1 \%$

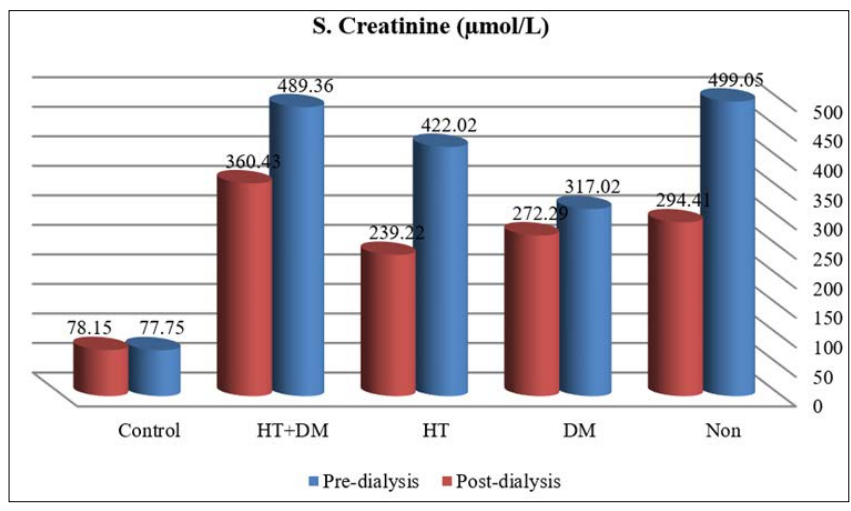

Figure 3.Serum Creatinine Concentration

Creatinine is released and withdrawn from skeletal muscle through the kidney; $\mathrm{Cr}$ is mostly released by the kidneys and predicted by GFR. ${ }^{26}$ In the patient group used during the investigation, a high significant increase in serum creatinine concentrations was identified, confirming the presence of renal failure. An ever-increasing concentration of serum creatinine is a highly specific biomarker of the loss of renal function. ${ }^{26}$ Creatinine is one of those compounds retained 
in uremic patients that is blood removed by haemodialysis because of the higher serum creatinine level in the blood of people with CRF. It is a decomposition product of creatine phosphate in muscle cells and the blood content is mostly dependent on muscle mass. It is eliminated by glomerular filtration from the plasma and subsequently expelled without significant reabsorption by the tubules in the urine. Increased serum creatinine is the outcome of uremic retention but is also related to the breakdown of muscles. ${ }^{25}$

The findings indicate that there is a notable increase in serum concentration of each (MDA, urea and creatinine), in patients group as compared to the control group that needed an intensive concern and co-dialysis treatment(s).

\section{Conclusion}

According to the results of the present study, it can be concluded that in all chronic renal failure patients with or without any accompanying disease, lipid peroxidation is present in pre- and post-haemodialysis patients as well as patients with CRF have high levels of urea and creatinine compared with healthy groups.

\section{Ethical Clearance}

The Research Ethical Committee at scientific research by ethical approval of both environmental and health and higher education and scientific research ministries in Iraq.

\section{Funding: Self-funding \\ Conflict of Interest: None \\ References}

1. Agrawal M, Swartz R. Acute renal failure. Am Fam Physician. 2000 Apr;61(7):2077-88. [PubMed]

2. Anavekar NS, McMurray JJ, Velazquez EJ, Solomon SD, Kober L, Rouleau JL, White HD, Nordlander R, Maggioni A, Dickstein K, Zelenkofske S, Leimberger JD, Califf RM, Pfeffer MA. Relation between renal dysfunction and cardiovascular outcomes after myocardial infarction. N Engl J Med. 2004 Sep;351(13):1285-95. [PubMed] [Google Scholar]

3. Chambers JK. Fluid and electrolyte problems in renal and urologic disorders. Nurs Clin North Am. 1987;22(4):81526. [PubMed] [Google Scholar]

4. Ashok KJ, Sajida MP, Joseph S. Plasma ceruloplasmin in chronic renal failure patients undergoing haemodialysis. J Clin Diag Res. 2010;4:2058-60. [Google Scholar]

5. Battino M, Ferreiro MS, Gallardo I, Newman HN, Bullon P. The antioxidant capacity of saliva. J Clin Periodontol. 2002 Mar;29(3):189-94. [PubMed] [Google Scholar]

6. Beguin Y. Soluble transferrin receptor for the evaluation of erythropoiesis and iron status. Clin Chim Acta. 2003 Mar;329(1-2):9-22. [PubMed] [Google Scholar]

7. Almamoori AMJ, Alwan WK, Al-Jassani MJ, Khadairi
MM, Salh SM, Almamori NMJ. Evaluation of DNA damage and antioxidants defense systems in type 2 diabetes mellitus patients. Ann Trop Med Public Health. 2019;22(12):141-50. [Google Scholar]

8. Kedziora-Kornatowska KZ, Luciak M, Blasczyk J, Pawlak W. Lipid peroxidation and activities of antioxidant enzymes in erythrocytes of patients with non-insulin dependent diabetes with or without nephropathy. Nephrol Dial Transplant. 1998;13(11):2829-32. [PubMed] [Google Scholar]

9. Niki E, Yoshida Y, Saito Y, Noguchi N. Lipid peroxidation: mechanisms, inhibition, and biological effects. Biochem Biophys Res Commun. 2005 Dec;338:668-76. [PubMed] [Google Scholar]

10. Yfjord JE, Bodvarsdottir SK. Genomic instability and cancer: networks involved in response to DNA damage. Mutat Res. 2005 Dec;592:18-28. [PubMed] [Google Scholar]

11. Menden CE, Boian JM, Murthy L, Petering HG. Plasma antioxidant. J Anal Lett. 1977;10:197.

12. Meyer TW, Hostetter TH. Uremia. N Engl J Med. 2007 Sep;357(13):1316-25. [PubMed]

13. Mehdi WA. Determination of resistin and several antioxidants in sera of patients with chronic renal failure. Aust J Basic Appl Sci. 2011;5(8):196-203. [Google Scholar]

14. Kubrusly M, Oliveira CM, Santos DC, Mota RS, Pereira ML. A comparative analysis of pre- and post-dialysis albumin as indicators of nutritional and morbi-mortality risks in haemodialysis patients. J Bras Nephrol. 2012 Mar;34(1):27-35. [PubMed] [Google Scholar]

15. Michael IO, Gabreil OE. Chronic renal failure in children of Benin, Nigeria. Saudi J Kidney Dis Transpl. 2004 JanMar;15(1):79-83. [PubMed] [Google Scholar]

16. Mitch WE. Malnutrition: A frequent misdiagnosis for hemodialysis patients. J Clin Invest. 2002 Aug;110(4): 437-9. [PubMed] [Google Scholar]

17. Nguyen-Khoa $T$, Massy ZA, De Bandt JP, Kebede M, Salama L, Lambrey G, Witko-Sarsat V, Drueke TB, Lacour B, Thevenin M. Oxidative stress and haemodialysis: role of inflammation and duration of dialysis treatment. Nephrol Dial Transplant. 2001 Feb;16(2):335-40. [PubMed] [Google Scholar]

18. Nitescu N. Studies on pathophysiological mechanisms in experimental models of acute renal failure [thesis]. Goteborg, Sweden: Goteborg University, Institute of Clinical Sciences, Department of Anesthesiology and Intensive Care; 2007. 49 p. [Google Scholar]

19. Oka Y, Miyazaki M, Takatsu S, Kunitomo K, Kokumai $\mathrm{Y}$, Matsuda $\mathrm{H}$, Maruyama M. Lowering of oxidative stress in hemodialysis patients by dialysate cleaning: in relation to arteriosclerosis. Ther Apher Dial. 2004 Aug;8(4):313-9. [PubMed] [Google Scholar] 
20. Patel BN, Dunn RJ, Jeong SY, Zhu Q, Julien JP, David $\mathrm{S}$. Ceruloplasmin regulates iron levels in the CNS and prevents free radical injury. J Neurosci. 2002 Aug;22(15):6578-86. [PubMed] [Google Scholar]

21. Rayner HC, Pisoni RL, Bommer J, Canaud B, Hecking E, Locatelli F, Piera L, Bragg-Gresham JL, Feldman HI, Goodkin DA, Gillespie B, Wolfe RA, Held PJ, Port FK. Mortality and hospitalization in haemodialysis patients in five European countries: results from the Dialysis Outcomes and Practice Patterns Study (DOPPS). Nephrol Dial Transplant. 2004 Jan;19(1):10820. [PubMed] [Google Scholar]

22. Rosner $\mathrm{MH}$. Hemodialysis for the non-nephrologist. South Med J. 2005 Aug;98(8):785-91. [PubMed] [Google Scholar]

23. Rutkowski P, Malgorzewicz SM, Lysiak-Szydlowska W, Swierczynski J, Rutkowski B. Interrelationship between uremic toxicity and oxidative stress. J Ren Nutr. 2006 Jul;16(3):190-3. [PubMed] [Google Scholar]

24. Sarkar D, Latif SA, Aich J, Uddin MM, Uddin MM. Studies on serum creatinine and creatinine clearance in hypertensive patients. Bangladesh Soc Physiol. 2006;1:19-26. [Google Scholar]

25. Valko M, Leibfritz D, Moncol J, Cronin MT, Mazur $M$, Telser J. Free radicals and antioxidants in normal physiological functions and human disease. Int J Biochem Cell Biol. 2007;39(1):44-84. [PubMed] [Google Scholar]

26. Samuel VT, Johncy SS, Murthy JD, Rekha M, Poornima RT. Potential role of oxidative stress and antioxidant deficiency in pathogenesis of diabetic nephropathy. J Pharm Sci Res. 2011;3(2):1046-51. [Google Scholar] 